\title{
O ENSINO DE GERENCIAMENTO DE OBRAS EM CURSOS DE ARQUITETURA
}

DOI: 10.37702/2175-957X.COBENGE.2021.3730

Adalberto Matoski - adalberto@utfpr.edu.br UTFPR

Rua Deputado Heitor Alencar Furtado 5000

81280-340 - Curitiba - PR

PAULA TATIANY MENDES LOPES - paulalopes@alunos.utfpr.edu.br UTFPR

Rua Deputado Heitor de Alencar Furtado, 50005000

81280-340 - Curitiba - PR

Resumo: A construção civil também foi um setor duramente atingido pela pandemia do covid-19 em função dos impactos causados pelas medidas de distanciamento social. Esse aspecto reforçou a necessidade da correta aplicação dos conceitos de gerenciamento de obras, onde esses conceitos são inicialmente apresentados durante a graduação. Assim, o objetivo desse trabalho é caracterizar o ensino da gestão de obras em cursos de arquitetura identificando além do conteúdo a carga horária utilizada. O método adotado foi a pesquisa dos currículos e ementas dos cursos de graduação nas Instituições de Ensino. Como resultado observou-se que pouca atenção é dada a esse conteúdo e que existem cursos com um percentual próximo de $10 \%$ de sua carga voltada para esse tema o que pode indicar que há uma visão importante do gerenciamento de obras.

Palavras-chave: Gerenciamento de obras, arquitetura, ensino 


\section{O ENSINO DE GERENCIAMENTO DE OBRAS EM CURSOS DE ARQUITETURA}

\section{INTRODUÇÃO}

$\mathrm{Na}$ construção civil existem vários fatores que podem levar ao atraso da entrega de uma obra. Um dos fatores é justamente a gestão de obras, em que os recursos, financeiros e de pessoal, nem sempre são alocados e gerenciados de forma ideal. Também fazem parte do gerenciamento os planos de comunicação, de qualidade, de custos, de prazos, entre outros, mostrando assim a sua amplitude e a importância.

Segundo Juliana Nakamura (2014), em seu artigo "Como fazer o gerenciamento de obras", desde a graduação os arquitetos já são desmotivados a estudarem sobre o assunto, visto que os cursos de arquitetura apresentam pouco conteúdo a respeito do tema, não despertando assim, interesse e curiosidade nos alunos. Ainda segundo a autora, existe uma ideia preconcebida de que os engenheiros são mais capazes de lidar com os assuntos que acercam o gerenciamento, como cronogramas, planilhas e orçamentos.

A empresa de consultoria Deloitte realizou em 2014, juntamente com o SINDUSCON (Sindicato da Indústria da Construção Civil), uma pesquisa sobre gestão orçamentária que consistia em mapear as dificuldades que as empresas do setor da construção civil tinham com relação ao seu planejamento orçamentário (DELOITTE TOUCHE TOHMATSU LIMITED, 2014). Os resultados foram consideráveis, pois o desvio médio entre os gastos previstos e reais foi, em média, de $21,7 \%$. Considerando esses aspectos o objetivo deste trabalho é caracterizar o ensino da gestão em cursos de arquitetura e identificar a profundidade em que é ensinado o gerenciamento de obras.

A importância da gestão de obras pode ser justificada pois devido as constantes mudanças, no que se refere a tecnologia para atender o mercado atual todo aprimoramento profissional é necessário pois existe uma demanda crescente por uma produção eficaz, onde não deve haver desperdício de energia, tempo, material e esforço humano. Para isso são necessários profissionais versáteis, com múltiplas habilidades e flexíveis (BERTOLI, 2011).

Esse artigo tem como objetivo, utilizando como método a análise de ementas de matérias de cursos de graduação que possuam esse conteúdo, caracterizar o ensino da gestão de obras em cursos de arquitetura identificando além do conteúdo a carga horária utilizada no ensino da gestão de obras. 


\section{REVISÃO BIBLIOGRÁFICA}

O gerenciamento de projetos consiste em um conjunto de princípios, práticas e técnicas aplicadas, cujo objetivo é liderar grupos de projetos e controlar sua programação, custos, riscos e outras variáveis, a fim de se obter êxito na entrega do produto final, utilizando-se de duas etapas fundamentais: planejamento e controle, como exemplificado no quadro abaixo (CAMPOS, 2012):

Figura 1: Gestão de projetos

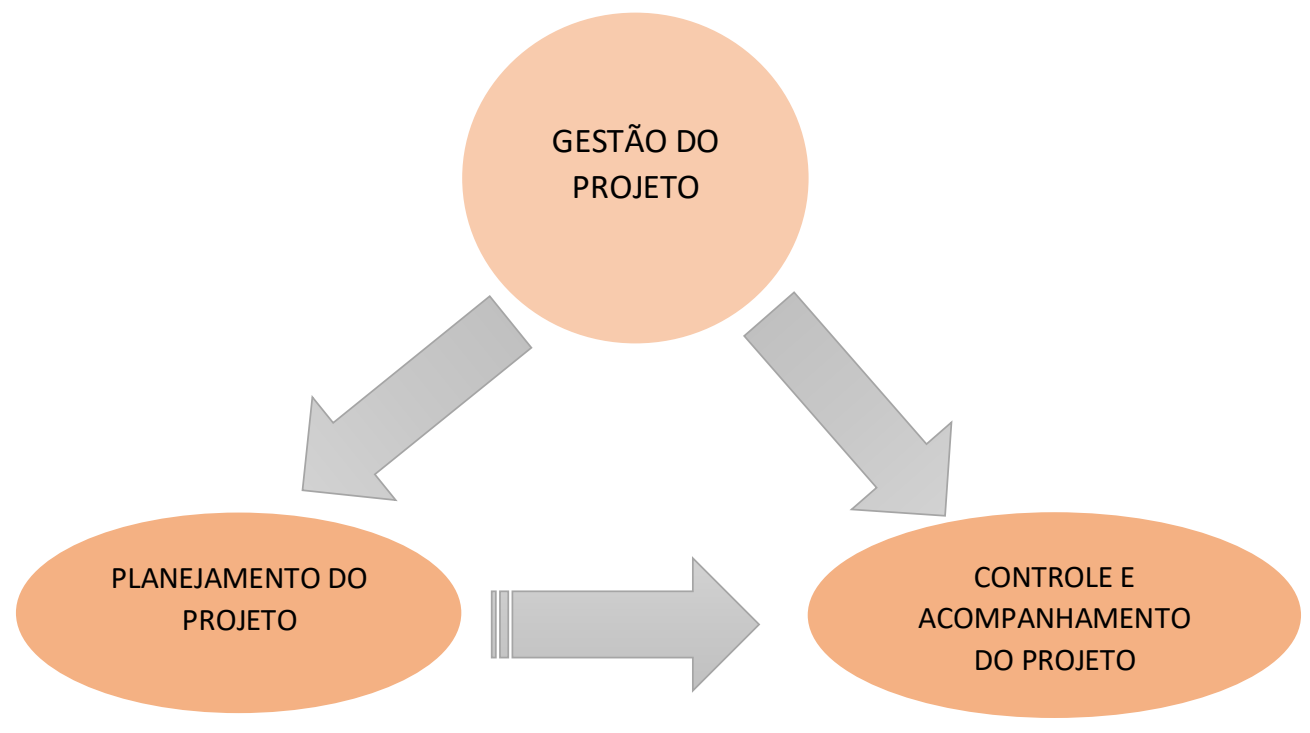

Fonte: Os autores, adaptado de Campos (2012)

Uma das ferramentas utilizadas no Gerenciamento de projetos é a EAP (estrutura analítica de projeto), que, para Avila e Jungles (2009), consiste em ordenar as atividades que serão realizadas segundo uma ordem cronológica e lógica de execução. Ainda segundo os autores, a EAP fala quais os responsáveis pelas tarefas, a duração delas, quais equipamentos são necessários para cada uma e os custos que as envolvem.

Para qualquer processo de gerenciamento de projetos é necessário que se tenha uma EAP, que é o conjunto de tarefas a serem realizadas, a duração de cada uma delas, a correlação entre as atividades e o nível de controle desejado, tudo isso unido em um só documento, denominado programação (AVILA e JUNGLES, 2009).

Para a construção civil não é diferente, o gerenciamento de obras é fundamental pois, para Mattos (2010), todo empreendimento deste tipo precisa obedecer a uma dada sequência lógica para o desenvolvimento do seu produto final. Ainda segundo o autor, todas as atividades do ciclo de vida de um projeto de construção civil, precisam ser desenvolvidas em tempo hábil e cada fase gera produtos que que são as entradas para as etapas subsequentes.

Segundo Nakamura (2014), gerenciar uma obra é administrar de forma conjunta o cumprimento do cronograma e a previsão financeira, além de gerir os profissionais, cujas formações e práticas, são das mais diversas. Ainda segundo autora, vários itens devem fazer parte do escopo do projeto, como: planejamento físico-financeiro da obra, 
programação das aquisições e cronograma de suprimentos, planejamento operacional e logístico do canteiro, controle e acompanhamento das atividades, retroalimentação do planejamento, entre outros.

O primeiro curso voltado para a arquitetura no Brasil se iniciou em 1826, na Academia Imperial de Belas Artes do Rio de Janeiro, que atendia estudantes de origem modesta, e foi o único no país por mais de 50 anos (Salvatori, 2008). Atualmente, em consulta ao portal do MEC (Ministério da Educação, 2019), verificou-se a existência de 692 cursos de graduação em arquitetura e urbanismo em atividade, enquanto nos anos 70 esse número girava em torno dos 30 , mostrando que em aproximadamente 40 anos a quantidade de faculdades ofertando o curso subiu consideravelmente, acompanhando o crescimento do ensino superior no Brasil.

No que se refere ao âmbito da gestão, estão inclusos os seguintes serviços como sendo de atribuição do arquiteto: coordenação e compatibilização de projetos, supervisão de obra ou serviço técnico, direção ou condução de obra ou serviço técnico, gerenciamento de obra ou serviço técnico, acompanhamento de obra ou serviço técnico, fiscalização de obra ou serviço técnico, desempenho de cargo ou função técnica (CAU, 2016). Abaixo uma tabela resumida com as atribuições dos arquitetos:

A construção civil é o ambiente empresarial sujeito a elevada competitividade, segundo Mutti (2008), criando a necessidade para as empresas fazerem melhor uso de seus recursos através de uma boa gestão e dando cada vez mais importância a fatores como a consciência ambiental, qualidade e satisfação dos envolvidos.

Para Magalhães, Mello e Bandeira (2018), a indústria da construção civil tem como uma de suas principais características a heterogeneidade e o uso intensivo de mão de obra, sendo a última, principalmente não qualificada. Ainda segundo os autores, esta atividade envolve uma quantidade muito grande de variáveis, com ambiente dinâmico e mutável, tornando o gerenciamento de obras um trabalho particularmente complexo.

A indústria da construção civil, além de representar $8 \%$ do PIB (Produto Interno Bruto) Nacional, também é uma grande empregadora, sendo este setor, o $4^{\underline{a}}$ maior gerador de empregos do país (MUTTI, 2008). Porém, para Alencar e Santana (2010), apesar da relevância e influência em âmbito nacional, o setor é considerado um dos menos desenvolvidos e mais tradicionais do Brasil.

\section{METODOLOGIA}

Para essa pesquisa foi feito um levantamento junto a cursos de Arquitetura e Urbanismo nas universidades do país em busca de suas matrizes curriculares, para identificar nelas a existência ou não de matérias ligadas ao gerenciamento de obras.

A pesquisa das matrizes curriculares, foi feita de forma identificar a existência de disciplinas que demonstrem o ensino do gerenciamento de obras. Essa pesquisa foi realizada através de buscas nos sites das próprias universidades onde foram escolhidos cursos de todas as regiões do estado e do país.

Após a identificação da disciplina seu conteúdo foi analisado e foi identificado a carga horária voltada para o aspecto gestão de obras. Esses valores foram tabulados e apresentados e forma de gráficos.

Para a elaboração dos gráficos utilizou-se como critério a identificação de disciplinas voltadas para gestão. Como por exemplo: Gestão de Projetos, Gerenciamento de Obras, Gerenciamento de Projetos e Obras, Gestão Financeira, Gestão de Obras e Serviços de 
Arquitetura e Urbanismo, Tecnologia das Construções e Orçamentos. Cabe ainda dizer que matérias de nomenclatura semelhante foram unidas em só grupo, como por exemplo: Tecnologia das Construções e Técnicas construtivas, ou Gerenciamento de Obras e Gestão de obras.

Além da quantificação foram analisadas as ementas resumidas de disciplinas relacionadas ao gerenciamento de obras de 10 cursos de arquitetura, de forma a propiciar uma amostra do que é ensinado em tais matérias. Todos os dados e análises estão baseados nas informações obtidas nas matrizes curriculares e ementas apresentada na internet, cujas datas de acesso estão citadas nas referências.

\section{RESULTAODS E DISCUSSÃO}

Dos 42 cursos analisados, $62 \%$ não possuem nenhuma matéria voltada a Tecnologia das Construções ou Gerenciamento. E, como mostra a figura 2 abaixo, 38\% dos cursos possuem alguma das seguintes matérias: Gestão de Projetos, Gerenciamento de Obras, Gerenciamento de Projetos e Obras e Gestão de Obras e Serviços de Arquitetura e Urbanismo.

Figura 2: Porcentagem de cursos com disciplinas voltadas para gestão

$$
\text { • Possuem matérias de Gerenciamento @ Não possuem }
$$

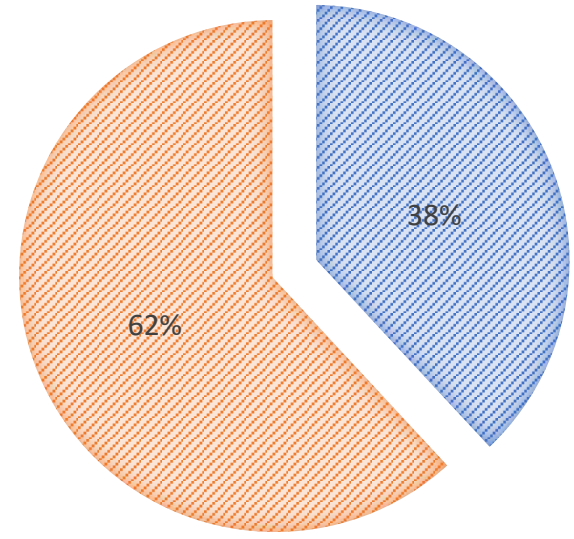

Fonte: Os autores

Cabe observar no entanto que . de acordo com Goes et al (2020), a integração de projetos possibilita reduzir eventuais erros ou falhas que seriam observadas somente no canteiro de obras. O mesmo autor cita que BIM (Building Information Modeling) é um método que permite realizar vários projetos simultaneamente além do projeto de arquitetura. Porém a implementação dessa plataforma tem um efeito multidisciplinar e por isso exige uma integração entre as mais diversas disciplinas que compõe um curso. Existe ainda um certo desconhecimento por parte de grande parte dos professores o que implica numa redução da velocidade da implantação completa da plataforma com o seu consequente aspecto multidisciplinar. 
A figura 3 apresenta uma relação da carga horária total das matérias relacionadas à tecnologia e gestão. Pode-se perceber que a maior parte dos cursos possuem soma da carga horária variando de 100 a 200 horas, enquanto apenas 4 deles apresentam carga horária superior a 300 horas.

Figura 3: Carga Horária Total

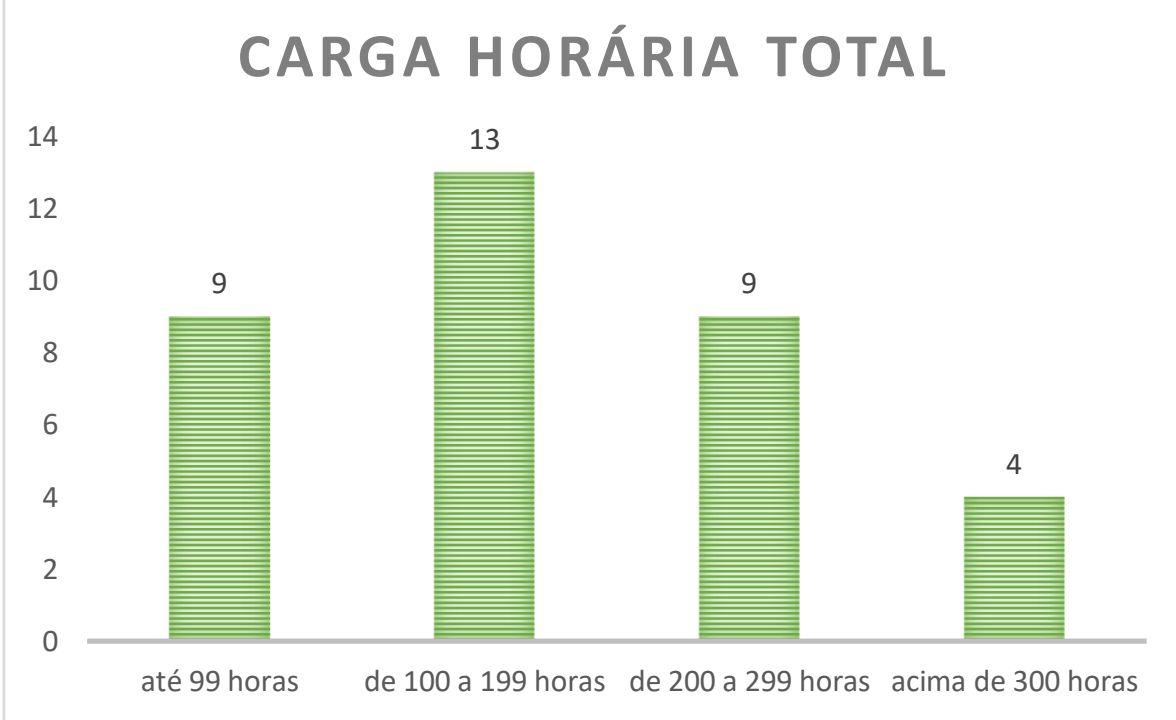

Fonte: Os autores

Observa-se assim que a quase totalidade dos cursos dedica um percentual da carga horário total da matriz curricular para os aspectos de gestão de obras. Com o crescimento da plataforma BIM em todas as áreas fica o desafio para os responsáveis de rever não só a matriz curricular mas a forma de gestão do próprio curso.

\subsection{Ementas}

$\mathrm{Na}$ primeira instituição analisada, conforme documento apresentado na internet, observa-se que dentre as disciplinas que dão suporte à gestão, estão as de tecnologia das construções, gestão de projetos e a de gerenciamento de obras. As primeiras apresentam ao estudante conteúdo sobre as etapas que se passam ao executar em uma obra. Gestão de projetos aborda os processos de gerência e a Estrutura Analítica de Projeto. Enquanto a matéria de gerenciamento de obras em contempla o planejamento de tempo, custos, alocação dos recursos, redes de precedência, além do planejamento e controle.

No segundo curso analisado também conforme informação obtida na internet temse disciplinas de tecnologia das construções com suas variações, inclusive uma delas tem foco em gerenciamento de obras. Nesta disciplina ensina-se sobre canteiro de obras, fluxos e toda a parte técnica relativa ao gerenciamento. Outras vertentes da tecnologia das construções ensinam o embasamento necessário ao gerenciamento, como orçamentos, materiais de construção e técnicas construtivas.

Em duas instituições de ensino estaduais observa-se a disciplina denominada de técnicas construtivas que aborda conteúdo voltado para o de gerenciamento de obras incluindo temas sobre orçamento e cronograma de obras. Também possuem disciplinas de técnicas construtivas, sendo que uma delas aborda a questão de cronograma de obras, coordenação de obras, rede de precedência, custos e canteiro de obras, conteúdos claramente voltados para a gestão de obras. 
Nas instituições de ensino particulares verificou-se a existência de um conjunto de disciplinas denominadas Canteiro Experimental, onde são contempladas as técnicas construtivas, canteiro de obras, materiais de construção, patologias e em pelo menos um semestre é dedicado ao estudo da gestão de obras, com técnicas de orçamentos, planejamento e organização de obras, qualidade e todo o processo de gestão de uma obra.

Em uma instituição que possui um dos mais bem conceituados cursos de arquitetura do Brasil observa-se a existência de pelo menos seis disciplinas que abordam conteúdos de gerenciamento de obras, expondo soluções construtivas, canteiro de obras, compatibilização de projetos e custos de obras da construção civil.

Algumas instituições particulares utilizam outras denominações como por exemplo aquelas denominadas como ateliê de projeto. Nessas disciplinas são abordados aspectos da tecnologia das construções, detalhes construtivos, emprego de materiais, técnicas construtivas e canteiro de obras.

Em parte das instituições federais possuem uma disciplina denominada Orçamento e Planejamento de Obras, em que aborda o gerenciamento e planejamento de empreendimentos, toda sua organização, os processos de orçamentação e o acompanhamento de projeto e de obras.

Cabe ressaltar ainda que pelo menos uma instituição federal daquelas que fazem parte da amostragem, possui uma expressiva carga horária (300 horas), de disciplinas técnicas, práticas e de gerenciamento de obras. As disciplinas técnicas abordam aspectos sobre canteiro de obras, materiais de construção e execução de edificações. Já as disciplinas denominadas práticas em obras mostram tecnologia das construções, noções de gestão e acompanhamento de obra. Por fim, a disciplina de gerenciamento de obras contempla aspectos de planejamento e controle de obras.

\section{CONSIDERAÇÕES FINAIS}

Como análise as ementas, pode-se observar que todos os cursos apresentam, cada um à sua forma, técnicas construtivas, fator muito importante para a compreensão do gerenciamento. Além disso, $60 \%$ dos cursos possuem a disciplina de o gerenciamento de obras em suas ementas.

Observou-se que os aspectos que envolvem o gerenciamento são ensinados em todas as universidades, como os conceitos gerais e as ferramentas de planejamento e controle.

O grande motor que pode impulsionar a melhoria dos aspectos de gestão nos cursos pode ser a plataforma BIM. Essa plataforma tem seu crescimento assegurado pela gestão governamental forçando as empresas adotarem esse caminho. Por sua vez as universidades e os respectivos cursos deverão seguir esse caminho sob pena de aumentar a defasagem entre o que é ensinado e a realidade profissional. O desafio para os responsáveis pelos cursos será a necessária mudança de estratégia no sentido de assegurar o aprendizado constante dos professores nessa nova tecnologia. $\mathrm{E}$ para isso as pessoas e ou órgãos (como o núcleo docente estruturante) que tem o poder da elaboração das estratégias do curso estejam dispostos e que sintam desejo de aprender o funcionamento dessas novas plataformas. Essas pessoas, além de serem proativas nas tomadas de decisões devem ser persistentes pois muitos imprevistos ao longo do processo ocorrem. 


\section{REFERÊNCIAS}

ALENCAR, Luciana Hazin; SANTANA, Marina de Oliveira. Análise do gerenciamento de múltiplos projetos na construção civil. Revista Gestão e Projetos v.1 n.1, São Paulo, 2010.

AVILA, Victorino Avila; JUNGLES, Antônio Edésio. Gestão do controle e planejamento de empreendimentos. Florianópolis: Florianópolis: CEPED UFSC - 2012.

BERTOLI, Fernanda et al. Habilitações e competências em gerenciamento de obras análise dos currículos e percepções de egressos dos cursos de arquitetura e urbanismo nas universidades do Paraná. Revista de Engenharia e Tecnologia, v.3, n.2, p.10-22, ago. 2011.

CAMPOS, Luiz Fernando Rodrigues. Gestão de Projetos. Instituto Federal do Paraná Curitiba, 2012.

GÓES, Matheus B. et al. -0 Benefícios da implementação do método BIM no planejamento e gerenciamento de obras - Revista Latino-americana de inovação e engenharia de produção nำ 14, v8 - Ouro Preto - 2020.

MATTOS, Aldo Dórea. Planejamento e controle de obras. $2^{a}$ ed. São Paulo: Oficina de textos, 2019.

MELLO, Luiz Carlos Brasil de Brito; BANDEIRA, Renata Albergaria. Planejamento e controle de obras civis: estudo de caso múltiplo em construtoras no Rio de Janeiro. Revista Gestão \& Projetos, vol.25, no. 1, São Carlos - SP, 2018.

NAKAMURA, Juliana. Como fazer o gerenciamento de obras. Disponível em: <http://au17.pini.com.br/arquitetura-urbanismo/245/como-fazer-o-gerenciamento-deobras-324017-1.aspx>. Revista AU, edição 245, 2014.

Pontifícia Universidade Católica do Paraná. Curso de Arquitetura e Urbanismo Disponível em: <https://www.pucpr.br/escola-de-arquitetura-edesign/graduacao/arquitetura-e-urbanismo/>. Acesso em: 19 dez. 2018.

SALVATORI, Elena. Arquitetura no Brasil: ensino e profissão. Arquitetura. Revista, vol.4, no. 2, Porto Alegre, 2008.

Universidade de São Paulo. Curso de Arquitetura e Urbanismo -. Disponível em: <http://www.fau.usp.br/graduacao/arquitetura-e-urbanismo/>. Acesso em: 19 dez. 2018.

Universidade Estadual de Londrina - Curso de Arquitetura e Urbanismo -. Disponível em: <http://www.uel.br/ctu/dau/curso.html>. Acesso em: 19 dez. 2018.

Universidade Estadual de Maringá - Curso de Arquitetura e Urbanismo -. Disponível em: <http://www.dau.uem.br/>. Acesso em: 19 dez. 2018. 
Universidade Federal da Integração Latino-Americana. Curso de Arquitetura e Urbanismo - Disponível em: <https://www.unila.edu.br/cursos/arquiteturaeurbanismo>. Acesso em: 19 dez. 2018.

Universidade Federal de Minas Gerais. Curso de Arquitetura e Urbanismo - Disponível em: <http://www.arq.ufmg.br/site/v2/>. Acesso em: 19 dez. 2018.

Universidade Federal do Paraná - Curso de Arquitetura e Urbanismo -. Disponível em: <http://www.cau.ufpr.br/>. Acesso em: 19 dez. 2018.

Universidade Federal do Rio Grande do Sul. Curso de Arquitetura e Urbanismo -. Disponível em: <https://www.ufrgs.br/comgrad-arq/>. Acesso em: 19 dez. 2018.

Universidade Paranaense - Curso de Arquitetura e Urbanismo -. Disponível em: <http://presencial.unipar.br/curso/graduacao/arquitetura-e-rbanismo/cascavel/presencial>. Acesso em: 19 dez. 2018.

Universidade Presbiteriana Mackenzie. Curso de Arquitetura e Urbanismo. Disponível em: <http://up.mackenzie.br/graduacao/sao-paulo/arquitetura-e-urbanismo/>. Acesso em: 19 dez. 2018.

Universidade Tecnológica Federal do Paraná - Curso de Arquitetura e Urbanismo -. Disponível em: <http://portal.utfpr.edu.br/cursos/graduacao/bacharelado/arquitetura-eurbanismo>. Acesso em: 19 dez. 2018.

\title{
WORK MANAGEMENT TEACHING IN ARCHITECTURE COURSES
}

\begin{abstract}
Civil construction was also a sector hard hit by the covid-19 pandemic due to the impacts caused by social distancing measures. This aspect reinforced the need for the correct application of construction management concepts, where these concepts are initially presented during graduation. Thus, the objective of this work is to characterize the teaching of construction management in architecture courses, identifying in addition to the content the workload used. The method adopted was to research the curricula and menus of undergraduate courses in educational institutions. As a result, it was observed that little attention is given to this content and that there are courses with a percentage close to $10 \%$ of its load focused on this theme, which may indicate that there is a important view of the management of works, despite the fact that assignment of these grades.
\end{abstract}

Keywords: Project management, architecture, education 